\section{Clinical Experience with the Dalkon Shield}

SIR,-Dr. J. S. Templeton (8 September, p. 542 ) is understandably disappointed at the results obtained with the Dalkon Shield at Southampton by $\mathrm{Mr}$. R. W. Jones and his colleagues (21 July, p. 143), and claims that multicentre studies for I.U.C.D. assessment should be obligatory in that overall figures for acceptability and reliability for any particular device can be better gauged by such studies.

I would take issue with this and argue that from a clinician's point of view the main advantage of a multicentre report is that it underlines the range of the results which are obtained. Thus Snowden and Williams found with the Dalkon Shield a pregnancy rate per 100 users after nine months of use which varied between 0.8 and 8.4 . Likewise, Tietze and Lewit, ${ }^{2}$ studying the $\mathrm{T} \mathrm{Cu} 200$ device in nine clinics found an overall pregnancy rate of 2.2 per 100 users, but at one centre the rate was 11.8

Bernard $^{3}$ and Snowden ${ }^{4}$ have investigated the reason for the marked discrepancy in results for the same device and have identified many factors. Some appear to be related to the doctor's skill and experience, others are patient-related-for example, her age, parity, religion, and use or not of additional contraceptive precautions. When choosing an I.U.C.D. for a particular patien the doctor should beware of relying too heavily on published data for overall device reliability.-I am, etc.,

St B rtholore: 's Hospital

Patricia Last

London E.C. 1

Snowden, R., and Williams, M., Contraception, Tietze, C., and Lewit, S., Studie: in Family Planning, 1972, 3, 277.

... American fournal of Public

gress Series, 1972, 260, 74.
.

\section{The Doctor's Attitude}

SIR,-In your discussion of the association between the social attitudes of psychiatrists and the treatments they recommend (29 September, p. 653) you point to the fact that such preferences are not based on reason alone but stem in part from deeper roots. There seems to be a remarkable consistency here that cuts across professional roles. My colleagues and I have found correlational similarities in a number of studies of nursing staff and psychiatric patients as well as doctors."-1 The "attitude to treatment questionnaire" that vou mention has to do with at titudes to discipline and organization, to the required degree of personal involvement with patients, to a formal versus an informal approach, to free communication, and to the fundamental scientific status of the work involved. Like doctors, nurses and patients differ radically between themselves on these issues, and the positions taken up are defended tenaciously and emotionally. ${ }^{1}$ Clearly very pervasive personality attributes are at issue.

The evidence suggests that doctors, nurses, and patients have the following characteristics in common. Those who adopt a scientific, physical, professional approach to psychiatric illness tend to adopt a traditionalis or "conservative" approach to many other aspects of life. They tend to be "outwardly" directed in their interests, preferring to deal with practical, concrete, realistic situations. They tend to be convergent thinkers, to use Liam Hudson's nomenclature. 5 That is, they prefer problems and situations that require a single correct answer for their solution.

On the other hand, staff and patients who adopt a psychological approach to psychiatric illness and treatment tend to be "liberal" or "revolutionary' in their apioroach to life. They are more "inwardly" directed in interest, preferring problems having to do with theories, philosophy, psychology, and religious mysticism. They are divergent thinkers in that they prefer situations or problems of a rather ambiguous kind lending themselves to more than one possible solution.

The treatment of psychiatric patients stretches the whole gamut of possibilities from the "revolutionary" socially oriented therapeutic community to the more "traditional" medically oriented physical treatments. The degree of active commitment and personal involvement on the part of the patient required in the treatment process varies considerably as one moves along the scale from psychotherapy to physical treatments In a somewhat similar way staff may be required to alter their attitudes and behaviour drastically in relation to the patient and each other as they move from a democratic to an authoritarian position.

Not all patients or all staff find these various treatment situations equally compatible. Our argument is that the more personally meaningful the situation is to both staff and patients, the more likely there is to be a successful therapeutic outcome. In order to achieve this match, more attention must be paid to staff and patient expectancies and underlying personality structure.-I am etc.,

P.ychology Department Woodford Bridge, Essex

Caine, T. M., in A Question of Attitudes, ed. D. Boorer, Appendix 1, p. 52. London, King Edward's Hospital Fund, Hospital Centre, 1970.
Caine, T. M. and Smail, D. I... The Treotment of Mental Il ness: Science, Faith and the Thera-
peutic Perconality. London, University of London Press, 1969

Caine, T. M.. and Leigh, R., Britich fournal of Social and Clinical Psychology. 1972, 11.52. Caine. T. M.. Wiiesinghe, B.. and Woot. R. R. British Fournal of Psychiatry, 1973, 122. 87. Hudson, L., Contrary Imaginations. Harmondsworth, Penguin Books, 1966.

\section{Propellant a Factor in Asthma Deaths?}

SiR,-Dr. V. E. Archer (29 September, p 696) blames you (leading article, 25 November 1972, o. 443) and me (30 December 1972 , p. 795) for overlooking the "strong possibility" that the propellant in aerosol cans might have contributed to the increase in asthma deaths. Far from it: I did not mention this possibility because it has been investigated by quite a number of authors ${ }^{1-6}$ who have not found it strong but rather remote. Surnrisingly, Dr. Archer auotes some of these papers ${ }^{3-6}$ in his favour. He also wrongly implies that other propellants than fluorocarbons which have been used in the U.S.A. for "aerosol sniffing" with fatal effect have been used in asthma. In his support of Stolley's ${ }^{7}$ epidemiological theory about the reasons for the 1967 peak in asthma mortality in the U.K. he overlooks the fact that, in addition to other incongruities of this theory, the Australian data show no evidence whatever to support an epidemiological relationship between any aerosol and the observed mortality.$^{89}$-I am, etc.,

London N.3

H. HERXHEIMER

1 Dollery, C. T., Draffan, G. H., Davies, D. S., Paterson, J. W., Sudlow, M., and Walker, S. R. Lancet, 1971, 2, 565 .

Clark, D. G., and Tinston, D. J., Annals of Mullin, L. S., Azar, A., Reinhardt, C. F., Smith P., and Fabryka, E. F., American Industria Hygiene Association fournal, 1972, 33, 389.

Azar, A., Zapp, J. A., Reinhardt. C. F., an Stopps, G. J., Fournal of the American Medical Association, 1971, 215, 1501 .

Brooks, S. M., Mintz, S., and Weiss, E. American

Stolley, P. D., American Review of Re-piratory Disease, 1972. 105, 883

Gandevia, B., Medical fournal of Australia, 1968 $1,884$.

press.

\section{Increase in Asthma Mortality}

SIR, - The rise and subsequent decline of asthma mortality in England and Wales and a number of other countries has been discussed at length for several years, many of the most relevant articles appearing in the B.M.F. One explanation suggested for the increase in mortality was that resistance developed to the sympathomimetic bronchodilators in nebulizers and that a crossresistance to endogenous sympathetic stimulation could have led to a deterioration of the asthmatic state in patients using the nebulizers. ${ }^{1}$ The purpose of this letter is to question this hypothesis and to propose an epidemiological study (if such a study has not already been conducted) which might lead to an alternative hypothesis to explain the increase in asthma mortality observed in some countries.

It is clear that some asthmatic patients are unresnonsive to sympathomimetic ${\text { bronchodilators. }{ }^{2} 3}$ But it is important to determine whether the asthmatic patient deteriorated before he became resistant to these drugs or whether he first became resistant to the drugs and his asthmatic condition then deteriorated. If resistance to the bronchiolar effects of sympathomimetic drugs was observed in patients whose asthma was not deteriorating, it would be so apoarent that a large body of literature would have developed. Instead, there are reports ${ }^{4}$ of long term usage of isoprenaline in nebulizers without the development of resistance.

Harris $^{67}$ has reported that the use of bronchodilator nebulizers has had little or no effect on asthma mortality and that the maior problem is that patients have been inadequately treated as the course of their disease worsened. Bronchodilators are not indicated as sole therapy for severe asthma and are relatively ineffective when used, thus conveying the impression of rapidly developing resistance. Under such conditions, and when increased mucus is present, rigorous medical treatment is necessary (such as hydration, positive pressure breathing, aspiration of secretions, antibiotics, corticosteroids, etc.). Harris ${ }^{7}$ reported that the leading cause of death from asthma is mucus plugging of bronchi. Herxheimer, who has frequently reported on the resistance of asthmatic patients to sympathomimetic aerosols, stated: ${ }^{2}$ "If their asthma gets worse 